\title{
Oral and vaginal route of misoprostol for induction of labour: a comparative study
}

\author{
Deepti D. Sharma ${ }^{1}$, Kavita A. Chandnani ${ }^{2 *}$
}

\begin{abstract}
${ }^{1}$ Department of Obstetrics and Gynecology, GMERS Medical College Gotri, Vadodara, Gujarat, India ${ }^{2}$ Department of Obstetrics and Gynecology, Shrimati Bhikhiben Kanjibhai Shah Medical Institute and Research Centre, Dhiraj General Hospital, Vadodara, Gujarat, India
\end{abstract}

Received: 23 February 2019

Accepted: 02 April 2019

\author{
*Correspondence: \\ Dr. Kavita A. Chandnani, \\ E-mail: kavyawch@rediffmail.com
}

Copyright: () the author(s), publisher and licensee Medip Academy. This is an open-access article distributed under the terms of the Creative Commons Attribution Non-Commercial License, which permits unrestricted non-commercial use, distribution, and reproduction in any medium, provided the original work is properly cited.

\section{ABSTRACT}

Background: Induction of labour can be defined as "Artificial initiation of uterine contractions before the onset of spontaneous labour, after the period of viability, by any methods, for purpose of vaginal delivery." The key factor for a successful induction is the status of cervix, its form, consistency and dilatation which is determined by the Bishop score. In case of unfavourable cervix or in the pregnancies remote from the term; prostaglandins are more effective than any other method of induction. Introduction of misoprostol, PGE1 analogue, for the induction of labour in 1993 and its approval for clinical use by ACOG (American College of Obstetrics and Gynecology) in 1999 has been the most significant advancement. It is the latest drug for induction of labour which is cheap and stable at room temperature and is being used worldwide in different doses and by various routes. We compared the most commonly preferred two routes; vaginal and oral in terms of success of induction and noted the adverse events and side effects in both routes.

Methods: This was a prospective comparative study carried out at SBKSMIRC (Shrimati Bhikhiben Kanjibhai Shah Medical Institute and Research Centre), Dhiraj general hospital, Vadodara, Gujarat, 200 patients who required induction of labour were recruited after applying inclusion and exclusion criteria and were randomly divided in two groups- Group A meant to receive $50 \mu \mathrm{g}$ oral misoprostol, Group B - meant to receive $25 \mu \mathrm{g}$ vaginal misoprostol repeated 4 hourly up to maximum of five doses. Progress of labour was charted on the partograph. The mean induction delivery interval, mode of delivery, maternal and neonatal outcomes and complications were observed.

Results: The mean induction to delivery interval was significantly less in vaginal group than oral $(23.3 \pm 12.4$ hours in oral vs. $17.3 \pm 10$ hours in vaginal). Vaginal delivery and cesarean section rates were comparable in both groups (76\% in Group A vs. $72 \%$ in Group B for vaginal delivery, $18 \%$ vs. $20 \%$ for Cesarean section, respectively). $58 \%$ patients in Group A required more than two doses as compared to $39 \%$ in group B, though the difference was statistically not significant. Significant number of patients required added oxytocin administration in Group A $(72 \%)$. No major complications or adverse events were observed. Neonatal hyperbilirubinemia was seen more in Group A.

Conclusions: Both Oral misoprostol in a dose of $50 \mu \mathrm{g}$ and vaginal misoprostol $25 \mu \mathrm{g}$ every four hours, to a maximum of five doses, have the potential to induce labour safely and effectively. The vaginal route however is beneficial in effecting delivery in lesser time with few numbers of doses as compared to oral route.

Keywords: Induction of labour, Misoprostol, Oral route, Vaginal route

\section{INTRODUCTION}

Induction of labour is one of the most important procedures in today's obstetrics. It has been a baffling problem since time immemorial and is most debatable when done prior to attainment of maturity or at term in normal patient, just to deliver her at the convenience of patient and the doctor, as failure of induction or meconium staining of liquor following induction can lead to increased incidence of cesarean sections. Normally, all 
pregnancies should continue to term and labour should begin spontaneously resulting in vaginal delivery, however Induction of labour is widely performed when continuation of pregnancy is hazardous to the mother or fetus. ${ }^{1}$ Induction of labour is the artificial initiation of uterine contractions before its spontaneous onset for the purpose of delivery of the fetoplacental unit using mechanical or pharmacological methods. ${ }^{2}$ The success of labour induction largely depends on the cervical status or Bishop's score at the time of induction. It is generally predicted that the patients with a poor Bishop's score at the initiation of induction have higher chances of failure of induction. ${ }^{3}$

A successful induction of labour refers to vaginal delivery of healthy baby, in an acceptable time frame with minimum maternal discomfort or side effects. ${ }^{4}$ The search for ideal agent, timing and route of administration for the induction of labour has been an ongoing process. The drugs commonly available for purpose of induction are oxytocin, dinoprostone gel and misoprostol.

Prostaglandin E2 has been the agent of choice for preinduction cervical ripening for several decades and is one of the pharmacologic agents approved by the United States Food and Drug Administration for this indication. However, it has several disadvantages: it is expensive, requires intracervical application, and continuous refrigeration. ${ }^{5,6}$ Induction of labour with oxytocin is unlikely to lead to vaginal delivery in an unripe cervix. ${ }^{7}$

Misoprostol (a prostaglandin E1 analogue) is a comparatively new agent for pre-induction cervical ripening and labour induction. It has excellent cervical ripening and uterotonic properties. $^{8}$ Although, misoprostol currently is approved by U.S. FDA for the prevention and healing of peptic ulcers induced by NSAIDs, in 2002, the U.S Food and Drug Administration approved a new label on the use of misoprostol during pregnancy for cervical ripening and for induction of labour. ${ }^{9,10}$ It is economical, stable at room temperature, with very few side effects and can be easily administered through oral, sublingual, vaginal , buccal or rectal routes. ${ }^{11}$ Most clinical trials have used doses ranging from $25 \mu \mathrm{g}$ to $100 \mu \mathrm{g}$, inserted intra-vaginally into the posterior fornix. ${ }^{3,10-14}$ The most common vaginal dose used has been $50 \mu \mathrm{g}$, inserted once or administered every four to six hours; inserting $25 \mu \mathrm{g}$ every six hours intravaginally has been associated with the fewest side effects. $^{5,14,15}$

Oral vs. vaginal route: Maximum plasma concentration of orally administered misoprostol is produced faster than vaginal method (30 minutes vs. 1 hour ), but the plasma concentration of the medication in vaginal method stay longer, so that oral misoprostol is removed after 2-3 hours, but vaginal misoprostol removal takes more than 4 hours. Although vaginal application of misoprostol has been validated as a reasonable means of induction, 5 there is patient resistance to repeated digital examination necessary for placement of the agent. There is also a risk of ascending infection because of repeated vaginal examinations. ${ }^{16}$

Oral misoprostol is well tolerated when used for the management of upper gastrointestinal tract dysfunction. ${ }^{9}$ For these reasons, oral administration of misoprostol has been introduced for cervical ripening and labour induction. ${ }^{17,18}$ It is not only easier, but mother satisfaction and acceptance is higher. There have been few trials assessing efficacy and tolerability of oral misoprostol for induction with varying conclusions.

Considering the routine use of both vaginal and oral routes, uncertainty regarding the preferred dose and route, lack of accurate statistics, advantages and disadvantages on the effectiveness of both methods, we designed this study to assess and compare the efficacy of oral misoprostol $50 \mu \mathrm{g}$ and vaginal misoprostol $25 \mu \mathrm{g}$ for induction of labour at term. And to compare maternal and neonatal complications and side effects of the drug.

\section{METHODS}

This was a prospective comparative study conducted in department of Obstetrics and Gynecology at SBKSMIRC (Shrimati Bhikhiben Kanjibhai Shah Medical Institute and research Centre), Dhiraj general hospital, Vadodara, from January 2010 to March 2011. Study population comprised of 200 subsequent pregnant women admitted through the emergency or outpatient department with an indication for induction of labour at term. After confirming eligibility criteria, informed written consent was obtained. To avoid observer bias, the patients were randomly assigned, by means of sealed envelopes handed over to designated staff unaware of dose and route written inside the envelope, to two groups -Group A, received tab misoprostol $50 \mu \mathrm{g}$ orally repeated every 4 hours for maximum five doses, group B received $25 \mu \mathrm{g}$ misoprostol vaginally every 4 hours for maximum of five doses.

\section{Inclusion criteria}

- Singleton pregnancy beyond 37 weeks gestation

- Vertex presentation

- Clinically adequate pelvis

- $\quad$ Bishop score $<6$

- Reactive Non stress test

- Absence of uterine contractions.

\section{Exclusion criteria}

- Malpresentation

- Presence of uterine contractions $>=3 / 10 \mathrm{~min}$

- Cephalo-pelvic disproportion

- Favourable cervix (Bishop score > 6)

- Previous Caesarean section or uterine scar

- Multiple gestation 
- Placenta previa

- Non reactive non stress test

- Contraindication to vaginal delivery

- Hypersensitivity to prostaglandins

- Parity -5 or more.

A detailed history, followed by general physical examinations was done. Obstetrical examination included fundal height, lie, presentation, fetal heart sound, per vaginal examination for assessing bishop's score and pelvis. Routine blood investigations and antenatal Ultrasound was done to ensure gestational age. Demographic characteristics were noted. Maternal vitals were monitored. Duration, frequency and intensity of uterine contractions were observed. Resident doctors on duty were instructed to ascertain proper execution of induction protocols. Study population was examined and misoprostol vaginally was placed in posterior fornix after moistening with saline by an assigned senior most resident only, at proper intervals. Per Vaginum examination was done every 4 hourly to note the changes in the status of cervix in both groups. Unnecessary PV examinations were strictly avoided to minimize the rate of infection. Fetal heart rate monitoring was done especially before each successive dose of misoprostol and induction continued only if fetal heart rate was normal. All parameters were charted on the partograph and progress of labour was assessed. Induction was discontinued when the patient entered in active labour which was considered if, either she had adequate uterine contractions rated as at least 3 contractions $/ 10$ min each of $40 \mathrm{sec}$ duration or the cervix was $>3 \mathrm{~cm}$ dilated. A further dose was withheld in cases of tachysystole, hyper tonus or hyper stimulation or non reactive CTG not corrected by primary measures which demanded intervention. If the patient did not enter active labour four hours after last dose, the induction was considered to have failed and cesarean section was performed. Amniotomy was done when cervix $>4 \mathrm{~cm}$ dilated, augmentation with oxytocin was done if patient failed to have good uterine contraction with frequency of at least 3 per 10 minutes 4 hours after last dose of misoprostol. Side effects and complications were noted. The outcomes were noted as

\section{Primary outcomes to evaluate efficacy were}

- Mode of delivery

- Induction-to-delivery interval in vaginal delivery

- Vaginal delivery within 24 hours.

The primary measures used to evaluate safety were the incidence of tachysystole (contraction pattern of more than six contractions in ten minutes), hypertonus (prolonged uterine contraction lasting more than two minutes), uterine hyper stimulation (hypertonus or tachysystole in the context of an abnormal fetal heart rate tracing requiring intervention); and non-reassuring FHR. ${ }^{19}$

\section{The secondary outcome measures included}

- Number of doses of misoprostol needed to effect vaginal delivery

- Augmentation with oxytocin

- Incidence of failed induction

- Maternal adverse effects (nausea/vomiting, diarrhea, fever, postpartum hemorrhage, uterine rupture)

- Neonatal outcomes.

\section{Statistical analysis}

Data was compiled tabulated and analyzed using SPSS vn 15. Chi square test was applied with $\mathrm{p}$ value of $<0.05$ considered as significant. Mean and standard deviation was calculated for descriptive statistics.

\section{RESULTS}

Table 1 depicts the demographic variables of the study group with regards to age, gestational age, parity and pre induction Bishop Score, which were comparable in both the groups. Mean age of patients was $25.10 \pm 3.4$ years in Group A (oral group) and 24.05 \pm 2.88 years in Group B (vaginal group). Average gestational age was 39.81 \pm 1.06 weeks and $40.07 \pm 1.00$ weeks in Group A and B, respectively. The mean Pre induction Bishop Score was 3.98 in oral group and 4.04 in vaginal group which was again comparable. Most women in each group were nulliparous (65\% in Group A, 68\% in group B).

Table 1: Demographic distribution of study population.

\begin{tabular}{|lll|}
\hline Characteristics & $\begin{array}{l}\text { Group A } \\
(\mathrm{n}=100)\end{array}$ & $\begin{array}{l}\text { Group B } \\
(\mathrm{n}=100)\end{array}$ \\
\hline $\begin{array}{l}\text { Maternal age, years } \\
\text { mean } \pm \text { SD }\end{array}$ & $25.10 \pm 3.4$ & $24.05 \pm 2.88$ \\
\hline $\begin{array}{l}\text { Gestational age, weeks } \\
\text { mean } \pm \text { SD }\end{array}$ & $39.81 \pm 1.06$ & $40.07 \pm 1.00$ \\
\hline $\begin{array}{l}\text { Pre induction Bishop } \\
\text { score, mean } \pm \text { SD }\end{array}$ & $3.98 \pm 1.55$ & $4.06 \pm 1.35$ \\
\hline Parity & & \\
\hline Primigravida & 65 & 68 \\
\hline Multigravida & 35 & 32 \\
\hline
\end{tabular}

Table 2: Indications for induction of labour.

\begin{tabular}{|lll|}
\hline $\begin{array}{l}\text { Indication for } \\
\text { induction }\end{array}$ & $\begin{array}{l}\text { Group A } \\
(\mathbf{N} \%)\end{array}$ & $\begin{array}{l}\text { Group B } \\
(\mathbf{N} \%)\end{array}$ \\
\hline Post date & 40 & 48 \\
\hline IUGR & 15 & 16 \\
\hline Severe PET & 17 & 14 \\
\hline Oligohydramnios & 20 & 14 \\
\hline IUFD & 3 & 2 \\
\hline Eclampsia & 2 & 4 \\
\hline Congenital anomalies & 03 & 02 \\
\hline
\end{tabular}


Table 2 enumerates indications for induction of labour. Post datism was the commonest indication for induction of labour comprising $48 \%$ and $40 \%$ in vaginal and oral group respectively, followed by oligohydramnios and IUGR.

Among the primary outcomes compared (Table 3), spontaneous vaginal delivery and caesarean section rates were almost similar in both the groups, $76 \%$ in group $\mathrm{A}$ and $72 \%$ in group B, $18 \%$ in group A and $20 \%$ in group $\mathrm{B}$, respectively. There was no significant difference in the mode of delivery in two groups, however the induction to delivery interval was significantly less in vaginal group, group $\mathrm{B}, \quad(\mathrm{P}=0.0014)$. Among the patients delivered vaginally more than $50 \%$ patients delivered in less than 24 hours in both the groups ( $\mathrm{P}=0.69$ i.e. not significant).

Secondary outcomes are shown in Table 4. More than $50 \%$ patients in group A required more than two doses of misoprostol to effect delivery which was comparable to $44 \%$ in group B. $72 \%$ patients required oxytocin augmentation in oral group whereas only $48 \%$ in vaginal group which was significantly less $(\mathrm{P}=0.001)$. This was either due to ineffective or in-coordinate uterine contractions or poor effacement of cervix encountered in oral group.

Very few adverse events were encountered. Tachysystole developed in two women in group A and one women in group $\mathrm{B}(\mathrm{P}=0.38)$. Uterine hyper stimulation occurred in two women $(2 \%)$ in the vaginal misoprostol group only.

Both of these (nulliparous) women received tocolysis and underwent urgent delivery by CS. None of the patients developed hypertonus. Non-reassuring FHR patterns were defined as late deceleration, variable deceleration, prolonged deceleration, tachycardia, or reduced FHR variability which was comparable in both groups.

Table 3: Primary outcome variables.

\begin{tabular}{|llll|}
\hline Characteristics & Group A & Group B & P value \\
\hline Mode of delivery & & & \\
\hline Vaginal delivery & $76 \%$ & $72 \%$ & 0.41 \\
\hline Cesarean section & $18 \%$ & $20 \%$ & 0.88 \\
\hline Instrumental delivery & $6 \%$ & $17.3 \pm 10.9$ & 0.73 \\
\hline $\begin{array}{l}\text { Induction-vaginal delivery interval, hours, } \\
\text { mean } \pm \text { SD }\end{array}$ & $23.3 \pm 12.4$ & 62 & 0.0014 \\
\hline Vaginal delivery within 24 hours & 55 & & 0.69 \\
\hline
\end{tabular}

Table 4: Secondary outcome variables.

\begin{tabular}{|llll|}
\hline Characteristics & Group A & Group B & P value \\
\hline No. of doses & 12 & 17 & \\
\hline 1 & 30 & 44 & 0.085 \\
\hline 2 & 58 & 39 & 0.001 \\
\hline$>$ & 72 & 48 & 0.73 \\
\hline Oxytocin administration $(\mathrm{n}=\%)$ & 9 & 12 & 0.33 \\
\hline Failed induction & & & 0.72 \\
\hline Maternal side effects, $\mathrm{n}=\%$ & 15 & 2 & 0.6 \\
\hline Nausea/vomiting & 2 & 4 & \\
\hline Diarrhea & 2 & 4 & 0.38 \\
\hline Fever & 0 & 1 & 0.42 \\
\hline PPH & & & \\
\hline Adverse events, $\mathbf{n}=\%$ & 2 & 1 & 0.84 \\
\hline Tachysystole & 0 & 2 & 0.32 \\
\hline Hyperstimulation & 0 & 0 & \\
\hline Hypertonus & 12 & 8 & \\
\hline Nonreassuring FHR & & & \\
\hline Neonatal outcome, $\mathbf{n}=\%$ & 15 & 11 & \\
\hline Meconium stained liquor & 9 & 2 & \\
\hline NICU admission & 2 & 3 & \\
\hline 1 min APGAR $<7$ & 6 & & \\
\hline 5 min APGAR $<7$ & & & \\
\hline
\end{tabular}


Table 5: Comparison with other studies

\begin{tabular}{|c|c|c|c|c|c|}
\hline Outcome & Route & $\begin{array}{l}\text { Rehman et al } \\
(50 \mu g \text { PO vs. } \\
25 \mu \mathrm{g} \text { PV) }\end{array}$ & $\begin{array}{l}\text { Janice et al (50 } \\
\text { g PO vs. PV }\end{array}$ & $\begin{array}{l}\text { Jindal et al } \\
\text { ( } 50 \text { нg PO vs. } \\
\text { PV) }\end{array}$ & 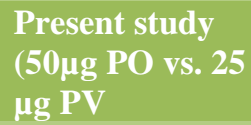 \\
\hline \multirow[t]{2}{*}{ Vaginal delivery } & Oral & $58 \%$ & $83.3 \%$ & $74.5 \%$ & $76 \%$ \\
\hline & Vaginal $(25 \mu \mathrm{g})$ & $64 \%$ & $76.8 \%$ & $90.38 \%$ & $72 \%$ \\
\hline \multirow[t]{2}{*}{ Cesarean section } & Oral & $30 \%$ & $16 \%$ & $25.49 \%$ & $18 \%$ \\
\hline & Vaginal & $29 \%$ & $19 \%$ & $9.62 \%$ & $20 \%$ \\
\hline \multirow[t]{2}{*}{$\begin{array}{l}\text { Induction to vaginal } \\
\text { delivery interval, } \\
\text { mean (SD), hours }\end{array}$} & Oral & $21.22 \pm 2.4$ & $27.3(18.8)$ & 16.47 & $23.3(12.4)$ \\
\hline & Vaginal & $20.15 \pm 3.1$ & $19.3(11.9)$ & 9.79 & $17.3(10.9)$ \\
\hline \multirow[t]{2}{*}{$\begin{array}{l}\text { Oxytocin } \\
\text { administration }\end{array}$} & Oral & $27.27 \%$ & $78 \%$ & - & $72 \%$ \\
\hline & Vaginal & $23.6 \%$ & $50 \%$ & - & $48 \%$ \\
\hline \multirow[t]{2}{*}{$\begin{array}{l}\text { Number of delivered } \\
\text { within } 24 \text { hours }\end{array}$} & Oral & $49 \%$ & $56 \%$ & $72.54 \%$ & $55 \%$ \\
\hline & Vaginal & $52 \%$ & $69.5 \%$ & $90.38 \%$ & $62 \%$ \\
\hline
\end{tabular}

Incidence of LSCS done for failed induction in oral group (A) was $9 \%$ whereas in vaginal group (B) was $12 \%$ $(\mathrm{P}=0.73)$. With regards to the neonatal outcome, no significant differences between the groups were found in the proportion of neonates with Apgar score $<7$ at 5 minutes, incidence of meconium-stained amniotic fluid, or the proportion admitted to NICU. Meconium stained liquor was seen in $15 \%$ in oral group and $11 \%$ in vaginal group. Nine babies from group A were admitted to NICU among which four had hyperbilirubinemia, two had mild respiratory distress, and two had feeding difficulties and one because of intrauterine growth restriction. In Group $\mathrm{B}$, the vaginal misoprostol group, three babies were admitted to NICU with suspected neonatal sepsis and one having had a seizure. The higher incidence of hyperbilirubinemia may be due to more requirement of oxytocin in Group A whereas neonatal sepsis in Group B may be attributed to frequent vaginal examinations needed. Maternal side effects were minimal and manageable with minimum interventions. PPH occurred in only one patient in vaginal group. Comparison with different studies is shown in Table 5. Our results were almost similar to that studied by, Janice et al, however, they had compared equivalent doses $\left(\begin{array}{lll}50 & \text { ug}\end{array}\right)$ of misoprostol by oral and vaginal routes. Rehman et al, compared $50 \mu \mathrm{g}$ orally administered to $25 \mu \mathrm{g}$ vaginally administered misoprostol and our findings were comparable with theirs. ${ }^{20,21}$

\section{DISCUSSION}

Preeclampsia The use of prostaglandin E1 analogue, Misoprostol for induction of labour has been quite promising. There is increasing evidence that misoprostol, administered either vaginally or orally, is as effective as conventional methods for induction of labour at term. ${ }^{22}$ Doses from $25 \mu \mathrm{g}$ to $200 \mu \mathrm{g}$ have been used but more than $50 \mu \mathrm{g}$ is associated with hyper stimulation, hypertonus, meconium stained liquor and uterine rupture. ${ }^{22}$

Distribution according to demographic characteristics in our study population was almost similar to study by Janice Sk et al, Rehman et al, and Shetty et al. ${ }^{20,21,23}$ This study shows that women who receive misoprostol vaginally experience faster induction-to-delivery times with less need for oxytocin augmentation when compared with a similar group of women receiving oral misoprostol. These findings concur with those of others. ${ }^{18,20}$ Though the total number of doses of misoprostol required in vaginal groups was lower as compared to oral, when average was derived, the difference was not statistically significant in our study which was in contrast to studies done by Wing DA et al, Janice SK et al, and Jindal et al. ${ }^{14,20,24}$ This may be due to the reason that sometimes the vaginal dose did not dissolute completely by the time of next dose which increased the requirement of dose. Induction to vaginal delivery interval was significantly lower in vaginal group as shown by Janice et al and Jindal et al, as vaginal misoprostol is absorbed rapidly and eliminated slowly from body making it available to act for a longer time as compare to oral resulting in rapid progression of labour. ${ }^{25}$ Main fear with this drug is sometimes excessive uterine contractions and possibility of uterine rupture in both scarred and unscarred uterus, however, by and large, use of this drug in previously scarred uterus is almost negligible and rupture is not common in primigravida and in multipara patients misoprostol is used very cautiously. These complications are dose related, higher the dose; more is uterine stimulation but shorter is the induction delivery interval. ${ }^{26}$ With $50 \mu \mathrm{g}$ vaginal misoprostol, incidence of uterine contractile abnormalities has been reported to be $4.9 \%, 9 \%$ and $12 \%$ in different studies. ${ }^{21,24,27}$ Ewert et al, observed these complications incidence as $6.25,10 \%$ with 100 and $200 \mu \mathrm{g}$ controlled 
release vaginal inserts of misoprostol, respectively. ${ }^{3,25,28}$ Higher incidence of fetal distress and meconium staining of liquor could be due to increase in hyper stimulation of uterus. Significantly increased number of patients required oxytocin augmentation in oral group compared to vaginal group in our study, an observation also noted by Rasheed R et al. ${ }^{29}$

There is extensive clinical experience with this agent (misoprostol) and a large body of published reports supporting its safety and efficacy when used appropriately. No studies indicate that intrapartum exposure to misoprostol or other PG cervical ripening agents does not have any long term adverse health consequences to the fetus in the absence of fetal distress nor there is a plausible biologic basis for such a concern. ${ }^{10}$ A limitation of our study may be no placebo control group; however certain indications definitely demand intervention in terms of induction of labour whatever be the preferred route and dose. Vaginal misoprostol significantly reduces the time interval to delivery and increases chances of vaginal delivery with less requirement of oxytocin, although cesarean section rates are no different from orally used misoprostol, making both routes comparable in outcomes, though higher dose is required when used orally due to reduced bioavailability and high first pass metabolism. Our study compared $50 \mu \mathrm{g}$ misoprostol orally vs. $25 \mu \mathrm{g}$ vaginally and findings were comparable with other studies. The acceptability to women of the different routes of administration should also be evaluated. Considering wide variation in preferences of dose and routes of misoprostol, recently, FIGO (2017) has come up with recent recommended regimens for misoprostol in different indications which allow inductions to be done with $25 \mu \mathrm{g}$ misoprostol vaginally every 6 hours or orally every 2 hours. ${ }^{30}$ Clinical trials have shown that at an equivalent dosage the vaginal route produces greater clinical efficacy than oral route. Approximately, $25 \mu \mathrm{g}$ of misoprostol should be considered as the initial dose for cervical ripening and labour induction. The frequency of administration should be not more than 3-6 hours. (Level A recommendation). ${ }^{10}$

\section{CONCLUSION}

The results of this study suggest that vaginal misoprostol is associated with shorter induction-to-delivery times than oral misoprostol. Mode of delivery may not be affected by the route preferred, but as on one side higher dose is required in oral route due to less bioavailability, vaginal administration on other hand may be bothersome and uncomfortable to the patient, thus affecting the compliance. Hence, there is a need for a greater number of appropriately designed double-blinded randomized controlled trials with a larger sample size to validate the efficacy and safety of $50 \mu \mathrm{g}$ oral misoprostol in comparison with $25 \mu \mathrm{g}$ vaginal misoprostol.
Funding: No funding sources

Conflict of interest: None declared

Ethical approval: The study was approved by the Institutional Ethics Committee

\section{REFERENCES}

1. National Institute of Clinical Excellence (NICE) clinical guideline 70. Induction of labour. London: NICE. 2008.

2. Rayburn COF. Pre induction cervical ripening. Basis and methods of current practice. ObstetGynaecol Survey. 2002;67:683-92.

3. Sanchez Ramos L, Kuntiz AM, Wears RL, Misoprostol for cervical ripening and labour induction: A Meta analysis. Obstet Gynaecol. 1997;89:633-42.

4. Ramsey PS, Ogburn P1, Jr. Harris DY, Heise RH, Ramin KD. Effect of vaginal PH on efficacy of misoprostol for cervical ripening and labour induction. Am J Obstet Gynaecol. 2000;182(6):16169.

5. Cheng S, Ming H, Lee J. Titrated oral compared with vaginal misoprostol for labour induction: a randomized controlled trial. Obstet Gynaecol. 2008;111:119-25.

6. Carlan SJ, Bouldin S, Biust Danielle O, Brien WF; safety and efficacy of misoprostol for labour induction. A randomized controlled trial. Obstet Gynaecol. 2001:98:107-12.

7. Pollnovv DM., BroeKhuizen FF. Randomized double blind trial of prostaglandin E2 intravaginal gel versus low dose oxytocin for cervical ripening before induction of labour. Am J Obstet Gynaecol. 1996;174:1910-16.

8. Off-label drug use and FDA review of supplemental drug applications: hearing before the subcommittee on Human Resources and intergovernmental relations of the committee on government reform and oversight, House of Representatives, 104th Congress, 2nd session, September 12. Washington: USGPO. 1996;53-94.

9. American College of Obstetricians and Gynecologists. New U.S. Food and Drug Administration labeling on Cytotec (misoprostol) use and pregnancy. ACOG Committee Opinion. Number 283, May 2003. Obstet Gynecol. 2003;101(5 Pt 1):1049-50.

10. ACOG practice bulletin: Clinical management guidelines for obstetricians and gynecologists. 2009:107.

11. Alfirevic Z, Keeney E., Dowswell T.,Welton NJ., Dias S., Jones LV. et al. Labour induction with prostaglandins, a systemic review and network meta analysis; BMJ. 2015:350;217-350.

12. Wing DA, Paul RH. A comparison of differing dosing regimens of vaginally administered misoprostol for preinduction cervical ripening and labour induction. Am J Obstet Gynaecol. 
1996;175:158-64. [Erratum in Am J Obstet Gynaecol 1997; 176:1423].

13. Kramer RL, Gilson GJ, Morrison DS, Martin D, Gonzales JL, Qualls CR. A randomized trial of misoprostol and oxytocin for induction of labour: safety and efficacy. Obstet Gynaecol. 1997;89:38791.

14. Wing DA, Paul RH. Misoprostol for cervical ripening and labour induction: the clinician's perspective and guide to success. Contemp Ob Gyn. 1999;44:46-61.

15. Hofmeyr GJ. Misoprostol administered vaginally for cervical ripening and labour induction in the third trimester [Cochrane Review on CD-ROM]. Oxford, England: Cochrane Library Update Software. 1998;3.

16. Alfirevic Z, Weeks A. Oral misoprostol for induction of labour. Cochrane Database Syst Rev. 2006:2:Art.CD001338.

17. Nagai SW, To WK, Lao T, Ho PC. Cervical priming with oral misoprostol in pre-labour rupture of membranes at term. Obstet Gynaecol. 1996;87:9236.

18. Windrim R, Bennett K, Mundle W, Young DC. Oral administration of misoprostol for labour induction: a randomized controlled trial. Obstet Gynaecol. 1997;89:392-7.

19. Curtis P, Evans S, Resnick J. Uterine hyper stimulation: the need for standard terminology. J Reprod Med. 1987;32:91-5.

20. Janice S. Kwon, Gregory AL. Paul Mackenzie A comparison of oral and vaginal misoprostol for induction of labour at term: a randomised trial. $\mathrm{Br} \mathrm{J}$ Obstet Gynaecol. 2001;108:23-6.

21. Rehman H, Pradhar A, Kharka L, Renjhen P, Kar S, Dutta S. Comparative evaluation of 50 microgram oral and 25 microgram intravaginal misoprostol for induction of labour at term: a randomized trial. $\mathbf{J}$ Obstet Gynaecol. 2013;35(5):408-16.
22. Fletcher HM, Mitchell S, Simeon D, Freidrick J, Brown D. Misoprostol for labour induction at term. Br J Obstet Gynaecol. 1993;100;641-4.

23. Shetty A, Danielian P, Templeton A. A comparison of oral and vaginal misoprostol tablets in induction of labour at term. BJOG. 2001;108(3):238-43.

24. Jindal P, Avasthi K, Kaur M. A comparison of vaginal vs. oral Misoprostol for induction of labourDouble Blind Randomized Trial. J Obstet Gynaecol Ind. 2011;61(5):538-42.

25. Drug Review. Misoprostol an old drug, new indications. Br J Postgrad Med. 2002;48(4):336-9.

26. How HY, Leasebevrge L, Khoury JC. A comparison of various routes and dosages of misoprostol for cervical ripening and the induction of labour. Am J Obstet Gynaecol. 2001;185.

27. Latika S, Biswajit C. Comparison of prostaglandin E1 (misoprostol) with prostaglandin E2 (dinoprostone) for labour induction. J Obstet Gynecol. 2004;54:139-42.

28. Evert K, Powers B, Robertson S. Controlled release misoprostol vaginal insert in parous women for labour induction. Obstet Gynaecol. 2006;108:1130-7.

29. Rasheed R, Alam AA, Younus S, Raza F, Oral vs. vaginal misoprostol for labour induction. J Pak Med Assoc. 2007;57(8):404-7.

30. WHO recommendations for induction of labour, 2011, Included in the WHO Model List of Essential Medicines, If only $200 \mu \mathrm{g}$ tablets are available, smaller doses can be made by dissolving in water Available at: www.misoprostol.org.

Cite this article as: Sharma DD, Chandnani KA. Oral and vaginal route of misoprostol for induction of labour: a comparative study. Int J Reprod Contracept Obstet Gynecol 2019;8:1956-62. 